\title{
Erratum
}

\section{Erratum to "Influential Factors of the Static Shear Properties of Coral Mud in the South China Sea"}

\author{
Yang Shen $\mathbb{D}^{1,2}$ Xiaoxi Rui $\mathbb{D}^{1,2}$ Long Yang $\mathbb{D}^{1,2}$ Shaoyu Li $\mathbb{D}^{1,2}$ and Xue Shen $\mathbb{D}^{1,2}$ \\ ${ }^{1}$ Key Laboratory of Geomechanics and Embankment Engineering of Ministry of Education, Hohai University, \\ Nanjing 210024, China \\ ${ }^{2}$ Jiangsu Research Center for Geotechnical Engineering Technology, Hohai University, Nanjing 210024, China \\ Correspondence should be addressed to Xiaoxi Rui; 18251877144@163.com
}

Received 11 October 2020; Accepted 11 October 2020; Published 27 October 2020

Copyright @ 2020 Yang Shen et al. This is an open access article distributed under the Creative Commons Attribution License, which permits unrestricted use, distribution, and reproduction in any medium, provided the original work is properly cited.

In the article titled "Influential Factors of the Static Shear Properties of Coral Mud in the South China Sea" [1], there was an error in reference [17], and the correct reference is shown as follows.

X. Wang, J. Cui, Y. Wu, C. Zhu, and X. Wang, "Mechanical properties of calcareous silts in a hydraulic fill island-reef," Marine Georesources \& Geotechnology, pp. 1-14, 2020. doi. https://doi.org/10.1080/1064119x.2020.1748775.

The error was introduced during the production process of the article, and Hindawi apologises for causing this error in the article.

\section{References}

[1] Y. Shen, X. Rui, L. Yang, S. Li, and X. Shen, "Influential factors of the static shear properties of coral mud in the South China Sea," Advances in Civil Engineering, vol. 2020, Article ID 8856987, 17 pages, 2020. 